\title{
Sources Identification of Nitrogen Using Major Ions and Isotopic Tracers in Shenyang, China
}

\author{
Huan Huang $\mathbb{D},{ }^{1}$ Mingzhu Liu $\mathbb{D},{ }^{1}$ Junjie Wang, ${ }^{2}$ Jiangtao He, ${ }^{1}$ and Honghan Chen ${ }^{1}$ \\ ${ }^{1}$ Beijing Key Laboratory of Water Resources \& Environmental Engineering, China University of Geosciences (Beijing), Beijing, China \\ ${ }^{2}$ Development Research Center of the Ministry of Water Resources of P.R. China, Beijing, China \\ Correspondence should be addressed to Mingzhu Liu; liumz@cugb.edu.cn
}

Received 17 October 2017; Revised 30 April 2018; Accepted 3 July 2018; Published 23 August 2018

Academic Editor: Meijing Zhang

Copyright (C) 2018 Huan Huang et al. This is an open access article distributed under the Creative Commons Attribution License, which permits unrestricted use, distribution, and reproduction in any medium, provided the original work is properly cited.

\begin{abstract}
Stable isotopes are natural tracers that can provide quantitative information about the surface water/groundwater interactions and sources of pollutants in water. In this study, we measured $\delta^{18} \mathrm{O}_{\text {water }}$ and $\delta^{2} \mathrm{H}_{\text {water }}$ and $\delta^{18} \mathrm{O}_{\text {nitrate }}$ and $\delta^{15} \mathrm{~N}_{\text {nitrate }}$ of the samples from the Hun River and groundwater in Shenyang City, China, where the water from the Hun River has a strong discharge and recharge connection with the groundwater. $\delta^{18} \mathrm{O}_{\text {water }}$ and $\delta^{2} \mathrm{H}_{\text {water }}$ were used to determine the amount of surface water that was discharged into groundwater, while $\delta^{18} \mathrm{O}_{\text {nitrate }}$ and $\delta^{15} \mathrm{~N}_{\text {nitrate }}$ were employed to determine the sources of nitrate and ammonium in groundwater, which are the main contaminants in the study area. The reducing environment in groundwater may result from the prevailing iron and manganese, occurring from weathering of minerals and rocks, which prevents the ammonium being oxidized into nitrate. Results show that the amount of recharge from the Hun River into groundwater accounts for around $55.56-86.60 \%$ of the total groundwater in the dry season, and the ratio changed to $30.97-63.79 \%$ in the wet season. Multiproxy analysis (stable isotope analyses in combination with chemical and hydrogeological data of the study area) indicates that human activities, such as manure and sewage discharge, are the prevailing source of nitrogen in the waters.
\end{abstract}

\section{Introduction}

Nitrogen pollution is an increasingly serious problem of groundwater in the riparian wellhead area of the Hun River. On the basis of the monitoring data of groundwater quality, nitrogen pollution has been found in most monitoring wells. Some water source wells have to be suspended, because the nitrogen content in groundwater exceeds the threshold in the Standard for Groundwater Quality (GB/T14848-93) in China. There are many sources of nitrogen pollution, and different sources cause different degrees of nitrogen pollution to groundwater. The groundwater source near the river plays an important role in the water supply in Shenyang. Therefore, it is of great significance to identify the source of groundwater nitrogen pollution and its contribution level and to carry out the targeted pollution control work and protect the groundwater resources.

Groundwater and surface water (such as rivers and lakes) are important components of the hydrological cycle, and they interact with each other in a variety of physiographic and climatic landscapes in the hydrologic system. Water quality and quantity from one component may have an influence on the other component in the hydrological cycle. Therefore, it is necessary to understand the basic principles of interactions between them, as well as spatial and temporal transformation rules of water quantity and quality between groundwater and surface water. These understandings will be of theoretical and practical significance with regard to assessment of water quantity and quality and further lead to the remediation, treatment, and prevention of water pollution [1-4].

The interaction between river water and groundwater is related to factors such as geography, landform, and rock characteristics of the water-bearing stratum, which are changing with seasons. In time and space, the transformation of groundwater and river water forms an indivisible complex system. Therefore, the chemical composition of water may be due to its long-term interaction with the surrounding 


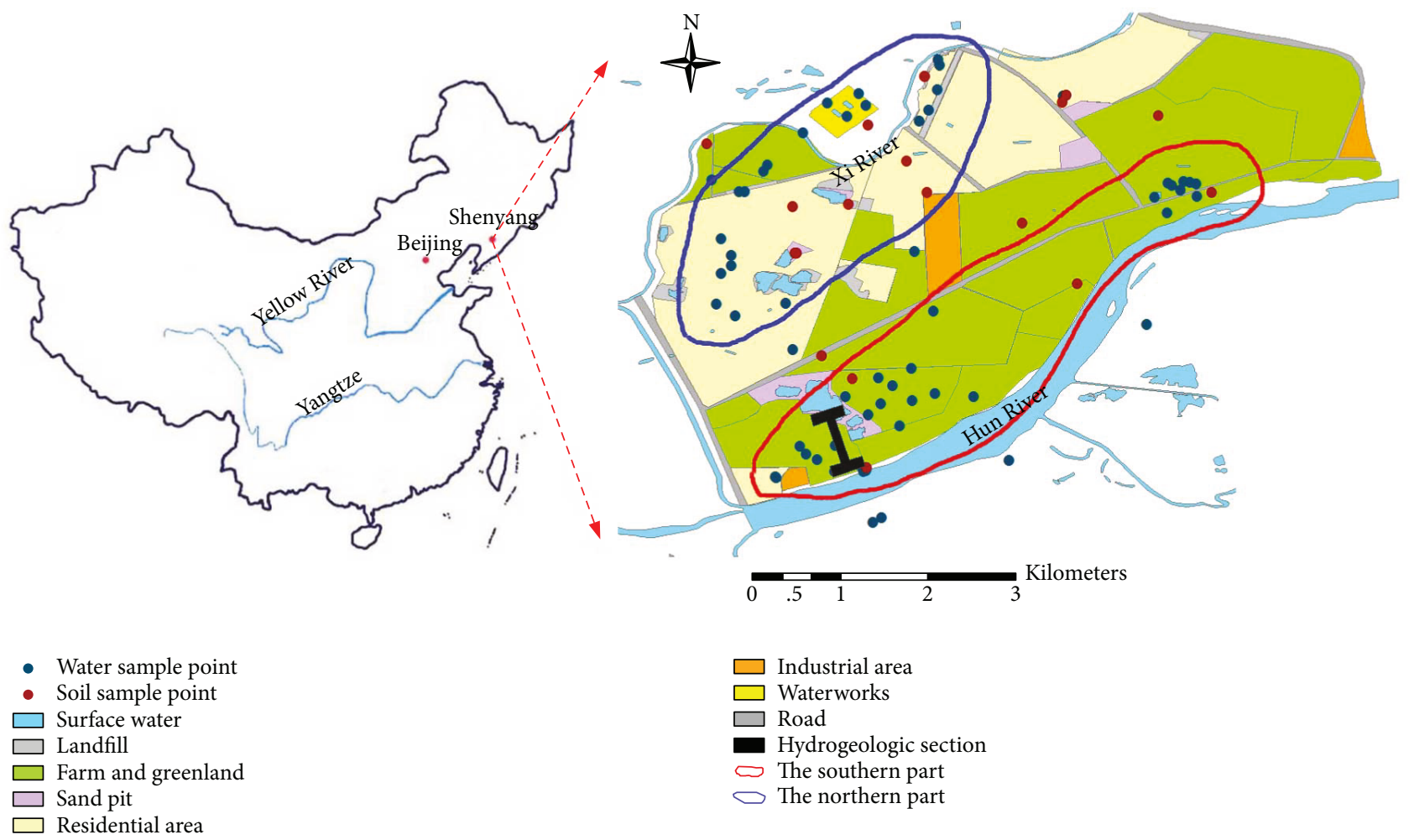

FIgURE 1: Location map of the study area. Modified from L. Y. Liu et al. [20].

environment in the water cycle. Moreover, water quality changes are usually caused by more complex interactions [3, 5-10]. Accordingly, the chemical composition of water can reflect its source information and evolution history to a certain extent, which will provide an effective tracing method for the study of the interaction between groundwater and surface water $[11,12]$. Researchers in different disciplines, such as geologists, hydrologists, and ecologists, are developing a more comprehensive conceptualization of groundwater and surface water interactions [13]; for example, Levy and $\mathrm{Xu}$ [14] review and compare methods to describe groundwater and surface water interactions at different scales and show typical applications in South Africa. Hayashi and Rosenberry [15] provide a comprehensive review for the effect of groundwater exchange on the hydrology and ecology of surface water. This work attempts to investigate the broader, multidisciplinary perspective of groundwater and surface water interactions, starting from some underlying prerequisites for comprehending environmental systems. To this end, we evaluate the hydrologic and water quality data for the Hun River basin, Shenyang city, China, to better understand the interactions between groundwater and surface water.

The main objective of the study was to identify the source(s) of nitrogen contamination in groundwater along the Hun River, Shenyang, China. To this end, the interactions between the Hun River and groundwater are analyzed with respect to the hydrogeology conditions of the site. $\delta^{18} \mathrm{O}_{\text {water }}$ and $\delta^{2} \mathrm{H}_{\text {water }}$ and $\delta^{18} \mathrm{O}_{\text {nitrate }}$ and $\delta^{15} \mathrm{~N}_{\text {nitrate }}$ were measured from the Hun River and groundwater to determine the amount of surface water that was discharged into groundwater as well as to track back the sources of the main contaminant. The approaches presented in this paper provide a framework for evaluating the importance of the interactions between groundwater and surface water in a human-natural coupled watershed.

\section{Geological Setting}

2.1. Description of Site. The study area lies in Shenyang city, Liaoning province, China, within latitudes $41^{\circ} 42^{\prime} 00^{\prime \prime} \sim$ $41^{\circ} 47^{\prime} 30^{\prime \prime}$ and longitudes $123^{\circ} 15^{\prime} 00^{\prime \prime} \sim 123^{\circ} 30^{\prime} 00^{\prime \prime}$ in the northeast of China. It is located between the $\mathrm{Xi}$ River and the Hun River and covers an area of about $36 \mathrm{~km}^{2}$ (Figure 1). The northern part of the study area was mainly residential and industrial land, which has a high intensity of contaminating sources. The south of the research area was the farmland and the green land with a relatively high intensity of contamination source.

2.2. Geology and Hydrogeology Conditions. The study area is located in the first terrace of the Hun River alluvialproluvial fan. The groundwater system consists of the phreatic aquifer and the leaky confined aquifer (Figure 2). The phreatic aquifer is composed mainly of medium sand and medium-coarse sand (hydraulic conductivity of ca. $\left.7 \times 10^{-4} \mathrm{~m} \cdot \mathrm{s}^{-1}[16]\right)$. The thickness of the phreatic aquifer is ca. $15 \mathrm{~m}$. The leaky confined aquifer is located below ca. $16 \mathrm{~m}$ from the surface, mainly composed of medium sand 
and medium-fine sand, with a thickness of ca. $15 \mathrm{~m}$. For the aquitard, it is located ca. $40 \mathrm{~m}$ below ground surface and composed mainly of clay and silty clay (hydraulic conductivity of ca. $8 \times 10^{-11} \mathrm{~m} \cdot \mathrm{s}^{-1}$ [16]). The groundwater table ranges from 10 to $12 \mathrm{~m}$ below ground surface, and the thickness of the aquitard is $4-6 \mathrm{~m}$.

\section{Sampling and Methodology}

Sampling conditions were shown in Table 1. The shallow well refers to the sampling well located in the phreatic aquifer, and the deep well refers to the sampling well located in the leaky confined aquifer. All water samples were collected in $50 \mathrm{~mL}$ high-density polyethylene bottles which were cleaned with detergent first, then with $10 \%$ nitric acid, and finally rinsed several times with distilled water. This procedure was carried out to ensure that the sample bottles we used were all free from contaminants.

In order to obtain the fresh aquifer samples for analysis, every borehole at the sampling point was pumped for about 5 minutes to purge the aquifer of stagnant water. Samples were initially collected in a sterilized bucket immediately after purging the aquifer and quickly transferred into the sampling bottles. Samples were taken in duplicate for major ion and stable isotope analyses. Some basic parameters of groundwater were measured directly in the field, including the temperature, $\mathrm{pH}$, dissolved oxygen (DO), total dissolved solid (TDS), and electrical conductivity (EC). Samples earmarked for major ion analyses were filtered on-site through $0.45 \mathrm{~mm}$ cellulose filters with the aid of a handoperated vacuum pump. The samples were kept in the refrigerator until they were transported to the laboratory for chemical analysis.

The major ions in the water at each sampling point were analyzed using a Dionex-120 ion chromatograph from the Laboratory of Environmental Chemistry, China University of Geosciences (Beijing). The accuracy of the analyses was estimated from the charge balance error (Freeze and Cherry, 1979 ), which is within $\pm 5 \%$ for all samples.

The stable hydrogen $\left({ }^{2} \mathrm{H}\right)$ and oxygen $\left({ }^{18} \mathrm{O}\right)$ isotopes in water collected in June 2011 (47 water samples) and September 2012 (54 water samples) were measured by a Picarro Isotopic Water Analyzer in the Water and WaterRock Reactions Isotope Laboratory, Institute of Geology and Geophysics, Chinese Academy of Sciences. The isotopic results of ${ }^{2} \mathrm{H}_{\text {water }}$ and ${ }^{18} \mathrm{O}_{\text {water }}$ were reported as $\delta^{2} \mathrm{H}_{\text {water }}$ and $\delta^{18} \mathrm{O}_{\text {water }}\left(\delta=\left(R_{\text {sample }} / R_{\text {standard }}-1\right) * 1000\right)$ in per mil (\%) data with the Vienna Standard Mean Ocean Water (VSMOW) standard. The analytical precision is $\pm 0.2 \%$ and $\pm 0.02 \%$ or for $\delta^{2} \mathrm{H}_{\text {water }}$ and $\delta^{18} \mathrm{O}_{\text {water, }}$, respectively.

The stable isotopes of nitrogen $\left({ }^{15} \mathrm{~N}\right)$ and oxygen $\left({ }^{18} \mathrm{O}\right)$ of nitrate in 26 water samples collected in June 2011 were analyzed in the Ministry of Land and Resources of Karst Geology Environmental Supervision and Testing Center using the anion exchange technique. The method for removing all O-bearing compounds from samples except $\mathrm{NO}_{3}{ }^{-}$and for removing the interference from other components to nitrogen measurement were based on a former paper reported by Silva et al. [17]. The stable isotopes of nitrogen $\left({ }^{15} \mathrm{~N}\right)$ and oxygen $\left({ }^{18} \mathrm{O}\right)$ of nitrate in 28 water samples and 11 soil samples collected in September 2012 were measured with the Isotope Mass Spectrometer MAT253 at the Soil and Environment Analysis and Testing Center, Nanjing Institute of Soil Sciences, Chinese Academy of Sciences, according to the method of Brand [18]. The ${ }^{15} \mathrm{~N}$ results were reported as $\delta^{15} \mathrm{~N}_{\text {nitrate }}$ relative to air in per mil (\%o) data. The analytical precision of $\delta^{15} \mathrm{~N}_{\text {nitrate }}$ and $\delta^{18} \mathrm{O}_{\text {nitrate }}$ was about $0.05 \%$ and $0.5 \%$, respectively.

\section{Results and Discussion}

4.1. Hydrochemistry Analysis. The statistical results of the chemical index of the samples of groundwater and surface water are shown in Tables 2 and 3. The variation range of $\mathrm{pH}$ in groundwater (both the southern and northern side of the study area) was 5.94-7.41, and the majority of the samples were within natural $\mathrm{pH}$ range of 6.50-8.50. The $\mathrm{pH}$ of surface water (Hun River) varied from 7.14 to 8.20 with a mean of 7.60, which was generally higher than the values in the groundwater. Lower $\mathrm{pH}$ of the water in the study area might be associated with $\mathrm{CO}_{2}$ produced by microbial respiration in the surface soil [19] or associated with local precipitation infiltration $[20,21]$. The $\mathrm{EC}$ results in groundwater ranged from 511.50 to $1783.00 \mu \mathrm{S} \cdot \mathrm{cm}^{-1}$, while the values for surface water ranged from 877.20 to $1231.90 \mu \mathrm{S} \cdot \mathrm{cm}^{-1}$. The standard of drinking water for EC values in the World Health Organization (WHO) was between 500 and $1500 \mu \mathrm{S} \cdot \mathrm{cm}^{-1}$ (Rodier, 1996), and some samples in both groundwater and the Hun River were higher than the standard value. From 2001 to 2005 , nearly 400,000 tons of domestic sewage water and a portion of industrial waste water were discharged into the Shenyang section of the Hun River without treatment every day (Lin et al., 2007); the polluted river recharged the aquifer and may lead to the increase of EC value. The relative errors of charge balance for all the elements in groundwater and river in June 2011 were $-1.53 \%$ and $-1.49 \%$, respectively, and those for March 2011 were $4.71 \%$ and $5.67 \%$, respectively.

From 2001 to 2005, the concentration of ammonium nitrogen (abbreviated as $\mathrm{NH}_{4}{ }^{+}-\mathrm{N}$ ) in the river water was as high as $9.72 \mathrm{mg} \cdot \mathrm{L}^{-1}$ to $22.35 \mathrm{mg} \cdot \mathrm{L}^{-1}$ (Lin et al., 2007). A high level of $\mathrm{NH}_{4}{ }^{+}-\mathrm{N}$ in moving water indicated some kind of contaminant entering the water. The Hun River of the study area was characterized by high levels of ammonium nitrogen concentrations, and all surface water samples exceeded the $0.5 \mathrm{mg} \cdot \mathrm{L}^{-1}$ limit specified by the WHO drinking water standard. The Hun River was close to heavily fertilized fields, and therefore, the manure and sewage discharged into the Hun River might contain a higher ammonium nitrogen.

In March 2011, the content of $\mathrm{NH}_{4}{ }^{+} \mathrm{N}$ in the water samples of the southern part was larger than that in the northern part. The content of $\mathrm{NH}_{4}{ }^{+}-\mathrm{N}$ in the Hun River had reached $6.09-12.12 \mathrm{mg} \cdot \mathrm{L}^{-1}$, and the groundwater sampling points of high concentration were located at the riverside. The groundwater level is lower than the river level due to the exploitation of water source wells. Therefore, it can be speculated that the ammonia in groundwater comes from the Hun River. In addition, fertilizers containing ammonium 


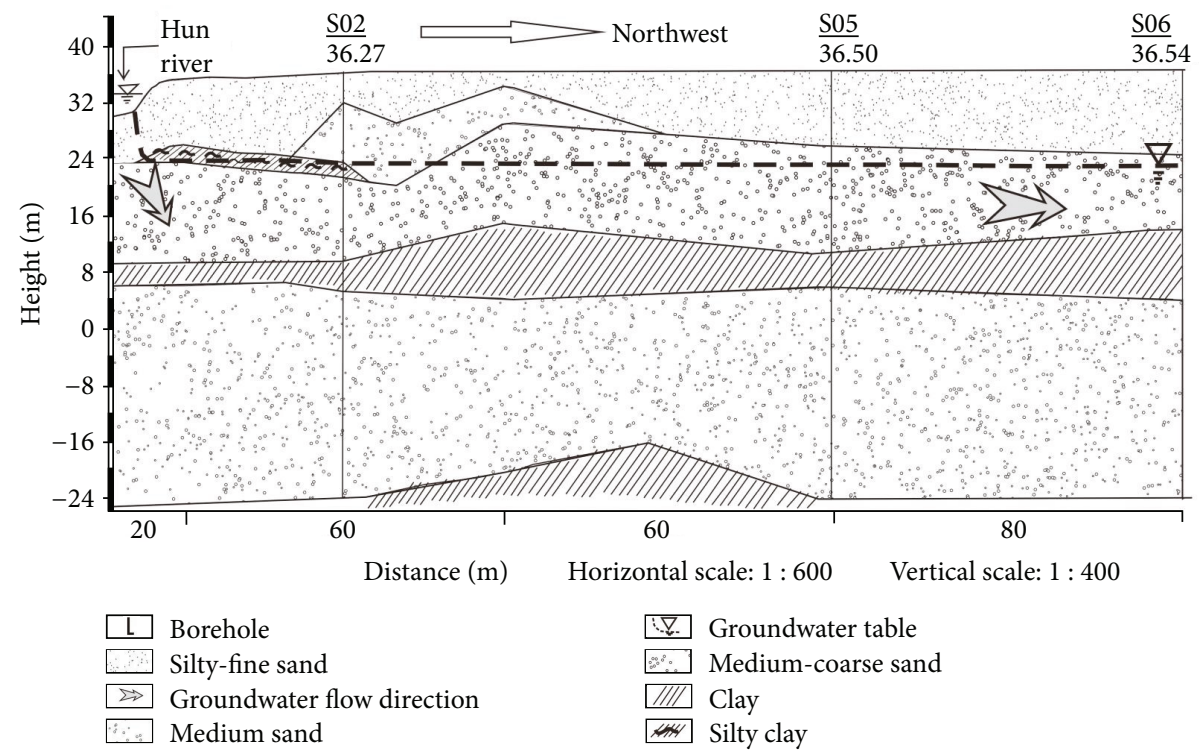

Figure 2: Hydrogeologic profile of the region near the Hun River. Modified from Hou et al. [16].

sulfate, $\left(\mathrm{NH}_{4}\right)_{2} \mathrm{SO}_{4}$, or ammonium nitrate, $\mathrm{NH}_{4} \mathrm{NO}_{3}$, might also result in a high level of ammonium ions in the samples. The most serious contaminants in the groundwater were $\mathrm{NH}_{4}^{+}-\mathrm{N}$, ranging from 0.02 to $24 \mathrm{mg} \cdot \mathrm{L}^{-1}$, which was followed by $\mathrm{NO}_{3}{ }^{-}-\mathrm{N}\left(0.16-71.50 \mathrm{mg} \cdot \mathrm{L}^{-1}\right)$, TFe $(0.05-$ $\left.12.92 \mathrm{mg} \cdot \mathrm{L}^{-1}\right)$, and $\mathrm{Mn}^{2+}\left(0.15-9.92 \mathrm{mg} \cdot \mathrm{L}^{-1}\right) . \mathrm{NH}_{4}{ }^{+}-\mathrm{N}$, $\mathrm{NO}_{3}{ }^{-}-\mathrm{N}, \mathrm{TFe}$, and $\mathrm{Mn}^{2+}$ concentrations at some locations exceeded the $0.5 \mathrm{mg} \cdot \mathrm{L}^{-1}\left(\mathrm{NH}_{4}{ }^{+}-\mathrm{N}\right), 11 \mathrm{mg} \cdot \mathrm{L}^{-1}\left(\mathrm{NO}_{3}{ }^{-}-\mathrm{N}\right)$, $0.3 \mathrm{mg} \cdot \mathrm{L}^{-1}(\mathrm{TFe})$, and $0.1 \mathrm{mg} \cdot \mathrm{L}^{-1}\left(\mathrm{Mn}^{2+}\right)$ limits specified by the WHO drinking water standard. The study area was a primary high iron and manganese groundwater zone [22]. The iron and manganese minerals in the study area were goethite, siderite, and rhodochrosite and contained a small amount of pyrite, magnetite, and pyrolusite [23]. The most common sources of $\mathrm{Fe}^{2+}, \mathrm{Fe}^{3+}$, and $\mathrm{Mn}^{2+}$ in groundwater were likely occurring naturally, from weathering of iron and manganese oxide minerals. However, industrial effluent, sewage, and landfill leachate might also contribute to $\mathrm{Fe}^{2+}$, $\mathrm{Fe}^{3+}$, and $\mathrm{Mn}^{2+}$ in groundwater $[24,25]$.

4.2. Groundwater Recharge. The geophysical investigation results showed that there was a close hydraulic connection between the phreatic aquifer in the study area and the Hun River. About 1 million cubic meters of groundwater were pumped every day from the Hun River aquifer for urban water supply, and a groundwater depression cone was formed, which causes continuous recharge of the river water to the phreatic aquifer. The phreatic aquifer and leaky confined aquifer are the main layers for groundwater exploitation in the area, and there is close hydraulic connection between the two aquifers [26]. The geophysical investigation results also revealed that there was a connection between the Hun River and the aquifer $60 \mathrm{~m}$ below the surface in the riverside area. As for the water quality, the Hun River, with a long history of pollution, also had a close relationship with groundwater. For example, the nitrogen concentration in groundwater was high, and a large portion was from the
TABle 1: Sampling conditions in different periods.

\begin{tabular}{lccc}
\hline Sampling time & March 2011 & June 2011 & September 2012 \\
\hline Deep wells & 29 & 49 & 27 \\
Shallow wells & 9 & 20 & 24 \\
Surface water & 7 & 10 & 7 \\
Soil samples & 0 & 0 & 13 \\
\hline
\end{tabular}

seepage of the Hun River, which had already been polluted by the manure and sewage and runoff from heavily fertilized fields, causing the river water to continuously recharge the phreatic aquifer.

4.3. Isotopic Compositions of Groundwater and the Hun River. Differences in the content of $\delta^{2} \mathrm{H}_{\text {water }}$ and $\delta^{18} \mathrm{O}_{\text {water }}$ of groundwater, rainfall, and surface water were used to determine the mixing processes in the groundwater flow system in the study area. $\delta^{2} \mathrm{H}_{\text {water }}$ and $\delta^{18} \mathrm{O}_{\text {water }}$ data typically were plotted on a diagram showing $\delta^{2} \mathrm{H}_{\text {water }}$ versus $\delta^{18} \mathrm{O}_{\text {water }}$ relative to VSMOW. Mean annual values of $\delta^{2} \mathrm{H}_{\text {water }}$ and $\delta^{18} \mathrm{O}_{\text {water }}$ in precipitation collected at many locations around the world plot along a line with a slope of 8 and an intercept of $+10\left(\delta^{2} \mathrm{H}=8 \delta^{18} \mathrm{O}+10\right)$, commonly referred to as the global meteoric water line (GMWL) [27]. The variability in isotopic composition of rainfall from one site to another is a function of several factors, including storm-track origin, rainfall amount and intensity, atmospheric temperature, and the number of evaporation and condensation cycles [28]. The stable isotopic composition of water relative to the GMWL revealed important information on groundwater recharge patterns, the origin of waters in hydrologic systems, and mixing of groundwater and surface water.

The exchange of water between river and aquifer could be traced by the difference in stable isotope composition between the regional groundwater and the river water. The 
TABle 2: Statistical summary of hydrochemical data in the Shenyang areas, March 2011. All units are in mg. $\mathrm{L}^{-1}$, except for electrical conductivity $\left(\mathrm{EC}, \mu \mathrm{S} \cdot \mathrm{cm}^{-1}\right)$.

\begin{tabular}{|c|c|c|c|c|c|c|c|c|c|}
\hline \multirow{3}{*}{ Parameter } & \multicolumn{6}{|c|}{ Groundwater } & \multirow{2}{*}{\multicolumn{3}{|c|}{ The Hun River }} \\
\hline & & uthern si & & & rthern si & & & & \\
\hline & Mean & Max & Min & Mean & Max & Min & Mean & Max & Min \\
\hline $\mathrm{pH}$ & 7.08 & 7.41 & 6.45 & 6.44 & 6.85 & 5.94 & 7.60 & 8.20 & 7.14 \\
\hline $\mathrm{EC}$ & 628.86 & 1035.00 & 511.50 & 1170.53 & 1783.00 & 650.60 & 1231.90 & 1652.00 & 877.20 \\
\hline $\mathrm{Ca}$ & 61.79 & 111.00 & 34.00 & 4.13 & 9.00 & 1.50 & 81.81 & 91.00 & 70.00 \\
\hline $\mathrm{Mg}$ & 19.16 & 35.00 & 1.00 & 41.53 & 85.00 & 18.00 & 25.54 & 32.00 & 20.00 \\
\hline $\mathrm{Na}$ & 48.09 & 70.83 & 29.92 & 71.13 & 113.90 & 33.43 & 110.84 & 182.20 & 50.69 \\
\hline K & 3.66 & 5.86 & 2.49 & 4.04 & 6.92 & 2.24 & 7.22 & 8.48 & 4.20 \\
\hline $\mathrm{Fe}$ & 1.13 & 5.16 & 0.06 & 2.62 & 23.86 & 0.13 & 1.59 & 4.93 & 0.99 \\
\hline $\mathrm{Mn}$ & 1.25 & 2.46 & 0.15 & 2.00 & 4.04 & 0.21 & 0.45 & 2.29 & 0.45 \\
\hline $\mathrm{NH}_{4}-\mathrm{N}$ & 2.55 & 12.11 & 0.03 & 0.14 & 0.68 & 0.03 & 12.12 & 19.00 & 6.09 \\
\hline $\mathrm{Cl}$ & 55.58 & 83.00 & 30.00 & 126.73 & 204.00 & 53.00 & 175.18 & 271.00 & 102.00 \\
\hline $\mathrm{HCO}_{3}$ & 189.77 & 259.16 & 98.13 & 153.97 & 236.47 & 70.45 & 201.29 & 228.97 & 178.65 \\
\hline $\mathrm{NO}_{3}-\mathrm{N}$ & 9.11 & 76.27 & 0.71 & 137.73 & 401.02 & 13.55 & 2.70 & 5.61 & 1.20 \\
\hline $\mathrm{SO}_{4}$ & 86.96 & 55.69 & 154.47 & 147.86 & 201.07 & 75.98 & 122.70 & 150.03 & 96.39 \\
\hline
\end{tabular}

TABLE 3: Statistical summary of hydrochemical data in the Shenyang areas, June 2011. All units are in mg. $\mathrm{L}^{-1}$, except for electrical conductivity $\left(\mathrm{EC}, \mu \mathrm{S} \cdot \mathrm{cm}^{-1}\right)$.

\begin{tabular}{|c|c|c|c|c|c|c|c|c|c|}
\hline \multirow{3}{*}{ Parameter } & \multicolumn{6}{|c|}{ Groundwater } & \multirow{2}{*}{\multicolumn{3}{|c|}{ The Hun River }} \\
\hline & \multicolumn{3}{|c|}{ Southern side } & \multicolumn{3}{|c|}{ Northern side } & & & \\
\hline & Mean & Max & Min & Mean & $\operatorname{Max}$ & Min & Mean & Max & Min \\
\hline $\mathrm{pH}$ & 6.86 & 7.32 & 6.15 & 6.61 & 7.06 & 6.22 & 7.26 & 7.36 & 7.02 \\
\hline $\mathrm{EC}$ & 690.18 & 1033.00 & 546.50 & 1356.37 & 2871.00 & 619.7 & 962.15 & 1399.0 & 474.8 \\
\hline $\mathrm{Ca}$ & 72.59 & 114.20 & 47.65 & 130.67 & 270.20 & 59.93 & 53.99 & 59.62 & 49.97 \\
\hline $\mathrm{Mg}$ & 17.34 & 27.75 & 11.77 & 34.78 & 52.64 & 12.98 & 12.86 & 15.96 & 11.77 \\
\hline $\mathrm{Na}$ & 52.19 & 67.34 & 33.66 & 81.89 & 132.10 & 38.98 & 30.71 & 35.48 & 27.61 \\
\hline $\mathrm{K}$ & 4.84 & 6.90 & 2.72 & 7.00 & 40.41 & 1.92 & 4.87 & 5.38 & 4.12 \\
\hline $\mathrm{Fe}$ & 0.89 & 6.49 & 0.02 & 1.21 & 11.79 & 0.03 & 0.35 & 0.61 & 0.19 \\
\hline $\mathrm{Mn}$ & 1.68 & 3.17 & 0.02 & 3.36 & 9.48 & 0.04 & 2.12 & 6.39 & 0.43 \\
\hline $\mathrm{NH}_{4}-\mathrm{N}$ & 1.10 & 4.79 & 0.06 & 2.51 & 17.53 & 0.03 & 0.07 & 0.12 & 0.05 \\
\hline $\mathrm{Cl}$ & 61.01 & 104.60 & 44.88 & 136.87 & 287.62 & 48.66 & 46.26 & 55.33 & 40.38 \\
\hline $\mathrm{HCO}_{3}$ & 214.38 & 281.14 & 123.17 & 268.22 & 527.50 & 93.71 & 143.27 & 123.20 & 179.40 \\
\hline $\mathrm{NO}_{3}-\mathrm{N}$ & 38.71 & 102.71 & 2.58 & 135.29 & 338.24 & 6.23 & 2.79 & 4.37 & 1.77 \\
\hline $\mathrm{SO}_{4}$ & 92.34 & 142.32 & 58.13 & 174.44 & 500.32 & 28.56 & 75.21 & 78.19 & 73.39 \\
\hline
\end{tabular}

results of stable isotope (Tables 4 and 5) showed clear mixing between shallow groundwater and surface water in the basin. In groundwater, the mean values of $\delta^{2} \mathrm{H}_{\text {water }}$ and $\delta^{18} \mathrm{O}_{\text {water }}$ for the dry season (June 2011) were -8.87 and $-65.12 \%$, respectively, and those for the wet season (September 2012) were -8.79 and $-65.64 \%$, respectively; because of the lag of river and precipitation recharge, the isotope content in the dry and wet periods is not significantly different. But in the Hun River, the mean values of $\delta^{2} \mathrm{H}_{\text {water }}$ and $\delta^{18} \mathrm{O}_{\text {water }}$ for the dry season (June 2011) were -9.16 and $-65.79 \%$, respectively, and those for the wet season (September 2012) were -9.54 and $-70.25 \%$, respectively. The values of $\delta^{2} \mathrm{H}_{\text {water }}$ and $\delta^{18} \mathrm{O}_{\text {water }}$ in the wet season were $-0.38 \%$ and $-4.46 \%$ o higher, respectively, than those in the dry season. Generally, the stable isotopic compositions of precipitation decrease with decreasing temperature and with increasing rainfall amount [29]. The results showed that the effect of precipitation amount was significant, and the stable isotope composition of precipitation decreased with the increase of rainfall amount and air temperature.

In Figures 3(a) and 3(b) (the size of the symbols represents the perpendicular distance of the sampling site measured from the Hun River), both $\delta^{18} \mathrm{O}_{\text {water }}$ and $\delta^{2} \mathrm{H}_{\text {water }}$ of the groundwater and surface water were located slightly lower than the local meteoric water line (LMWL), these suggesting that there was evaporation in the basin, and the 
TABLE 4: Statistical summary of $\delta^{18} \mathrm{O}_{\text {water }}(\%)$ and $\delta^{2} \mathrm{H}_{\text {water }}(\%)$ values of groundwater and river water in the study area.

\begin{tabular}{lcccccccc}
\hline & \multicolumn{4}{c}{ Dry season } & \multicolumn{2}{c}{ Wet season } & \multicolumn{3}{c}{ The Hun River } \\
& $\delta^{18} \mathrm{O}(\%)$ & $\delta^{2} \mathrm{H}(\%)$ & $\delta^{18} \mathrm{O}(\%)$ & $\delta^{2} \mathrm{H}(\%)$ & $\delta^{18} \mathrm{O}(\%)$ & $\delta^{2} \mathrm{H}(\%)$ & $\delta^{18} \mathrm{O}(\% \mathrm{o})$ & $\delta^{2} \mathrm{H}(\% \mathrm{o})$ \\
\hline Mean & -8.87 & -65.12 & -8.79 & -65.64 & -9.16 & -65.79 & -9.54 & -70.25 \\
Maximum & -7.82 & -58.77 & -6.90 & -55.30 & -8.90 & -64.3 & -9.14 & -67.60 \\
Minimum & -9.73 & -70.24 & -13.85 & -103.2 & -9.39 & -66.92 & -9.87 & -72.30 \\
\hline
\end{tabular}

TABLE 5: Statistical summary of $\delta^{18} \mathrm{O}_{\text {nitrate }}(\%)$ and $\delta^{15} \mathrm{~N}_{\text {nitrate }}(\%)$ values of groundwater and river water in the study area.

\begin{tabular}{lcccccccc}
\hline & \multicolumn{4}{c}{ Droundwater } & \multicolumn{2}{c}{ Wet season } & \multicolumn{2}{c}{ The Hun River } \\
& $\delta^{18} \mathrm{O}(\%)$ & $\delta^{15} \mathrm{~N}(\%)$ & $\delta^{18} \mathrm{O}(\%)$ & $\delta^{15} \mathrm{~N}(\%)$ & $\delta^{18} \mathrm{O}(\%)$ & $\delta^{15} \mathrm{~N}(\% \mathrm{o})$ & $\delta^{18} \mathrm{O}(\%)$ & $\delta^{15} \mathrm{~N}(\%)$ \\
\hline Mean & 10.87 & 6.17 & 5.04 & 9.74 & 13.05 & 3.25 & 3.16 \\
Maximum & 14.08 & 13.22 & 15.02 & 24.85 & 15.96 & 3.87 & 13.31 & 7.26 \\
Minimum & 7.36 & -3.14 & -18.36 & -7.26 & 10.13 & 2.63 & -10.36 & 3.80 \\
\hline
\end{tabular}

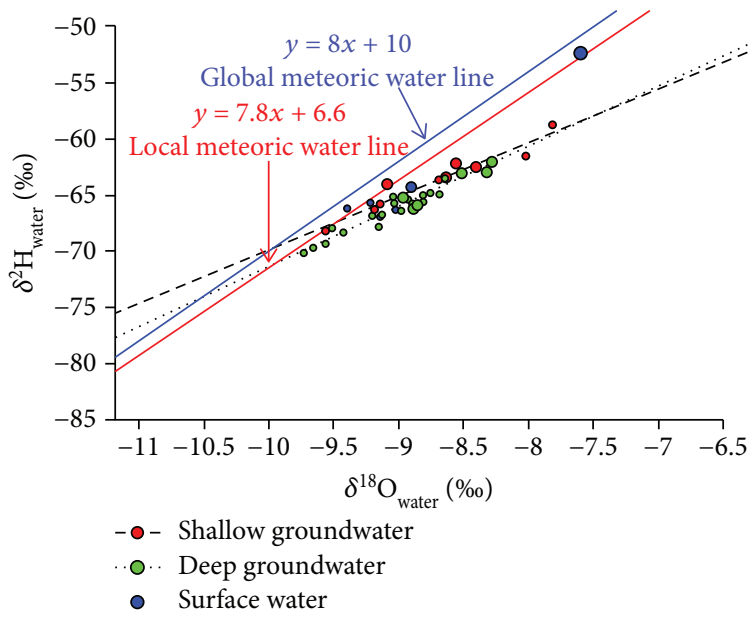

(a)

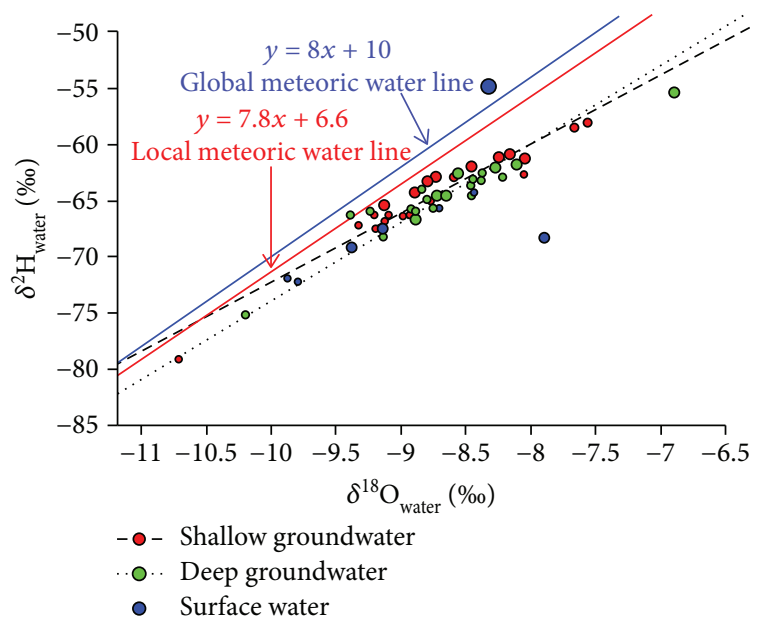

(b)

FIGURE 3: Plot of $\delta^{2} \mathrm{H}_{\text {water }}$ and $\delta^{18} \mathrm{O}_{\text {water }}$ for shallow groundwater, deep groundwater, and surface water samples collected in the study region: (a) dry season; (b) wet season.

groundwater was a mixture of river water and precipitation, and the influence of the river water recharge was greater than that of the infiltration.

In Figure 3, the distribution of deep groundwater and shallow groundwater was approximately the same, which was further consistent with the closely hydraulic connection between the two layers of aquifer. The points representing shallow groundwater were closer to the LMWL, and the phenomenon was more obvious in Figure 3(b) (wet season). This means that the phreatic aquifer was more affected by rainfall than the leaky confined aquifer. The values of $\delta^{18} \mathrm{O}_{\text {water }}$ and $\delta^{2} \mathrm{H}_{\text {water }}$ of the points far away from the river bank (larger symbols) were higher than those near the Hun River (smaller symbols). This indicates that the groundwater in the riverside area is more affected by the river. It receives the recharge of the Hun River, and the isotopic enrichment occurs at a distance from the river.
4.4. Mass Balance of Isotopic Compositions of Groundwater. Different stable isotopic compositions of ${ }^{2} \mathrm{H}_{\text {water }}$ and ${ }^{18} \mathrm{O}_{\text {water }}$ in groundwater were used to identify the mixing progress in the study area. The variability in isotopic composition of rainfall from one site to another is a function of several factors, including storm-track origin, rainfall amount and intensity, atmospheric temperature, and the number of evaporation and condensation cycles [28]. The stable isotopic composition of water relative to the GMWL revealed important information on groundwater recharge patterns, the origin of waters in hydrologic systems, and mixing of groundwater and surface water [30,31].

The isotopic composition of groundwater is equivalent to the average weighted value of recharge sources. Therefore, there are deviations in isotope ratios between groundwater and precipitation. Understanding the transfer function of precipitation to groundwater is crucial to the study of 
TABLE 6: The recharge ratios of the Hun River to the groundwater.

\begin{tabular}{|c|c|c|c|c|c|c|c|}
\hline Section & Point & Distance from Hun River $(\mathrm{km})$ & \multicolumn{2}{|c|}{$G(\%)$} & $R(\% \mathrm{o})$ & $P(\%)$ & $\theta(\%)$ \\
\hline \multirow{2}{*}{ I } & \multirow{2}{*}{ LG18 } & \multirow[b]{2}{*}{1.02} & $\delta^{18} \mathrm{O}$ & -8.69 & -9.14 & -7.59 & 70.97 \\
\hline & & & $\delta^{2} \mathrm{H}$ & -52.44 & -66.92 & -64.98 & 86.60 \\
\hline \multirow{2}{*}{ II } & \multirow{2}{*}{ ZK05 } & \multirow{2}{*}{0.66} & $\delta^{18} \mathrm{O}$ & -8.49 & -9.21 & -7.59 & 55.56 \\
\hline & & & $\delta^{2} \mathrm{H}$ & -52.44 & -65.7 & -63.45 & 83.03 \\
\hline \multirow{2}{*}{ III } & \multirow{2}{*}{ JS23-1 } & \multirow{2}{*}{0.41} & $\delta^{18} \mathrm{O}$ & -8.80 & -9.87 & -8.32 & 30.97 \\
\hline & & & $\delta^{2} \mathrm{H}$ & -54.90 & -71.90 & -64.90 & 58.82 \\
\hline \multirow{2}{*}{ IV } & \multirow{2}{*}{ LG42-2 } & \multirow{2}{*}{0.47} & $\delta^{18} \mathrm{O}$ & -8.88 & -9.79 & -8.32 & 38.10 \\
\hline & & & $\delta^{2} \mathrm{H}$ & -54.90 & -72.30 & -66.00 & 63.79 \\
\hline
\end{tabular}

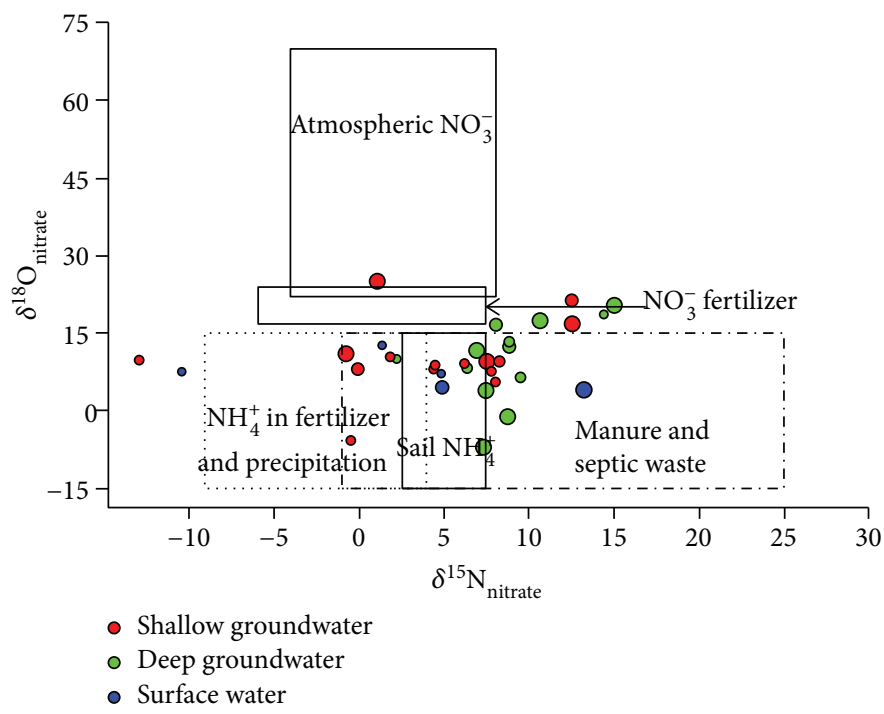

FIgURE 4: Dual-isotope method for nitrate source attribution in groundwater, September 2012. Modified from Fenech et al. [33].

groundwater sources. The transfer function can provide basic information of recharge mechanism [32].

Groundwater in the study area was recharged by rainfall and river water. In the study of basin water balance, it was important to assess the actual recharge of groundwater by rainfall and river water. The stable isotopes of groundwater were determined by the percentage of recharge from the relevant sources. It is assumed that the groundwater in the vicinity of the study area is a mixture of the Hun River and the precipitation. Based on the mass balance calculation of oxygen and hydrogen isotopes, the contribution percentage of each recharge source to groundwater in the study area could be evaluated by the following equation:

$$
\begin{aligned}
G\left(V_{\mathrm{P}}+V_{\mathrm{R}}\right) & =P V_{\mathrm{P}}+R V_{\mathrm{R}}, \\
G & =P \frac{V_{\mathrm{P}}}{V_{\mathrm{P}}+V_{\mathrm{R}}}+R \frac{V_{\mathrm{R}}}{V_{\mathrm{P}}+V_{\mathrm{R}}}=P(1-X)+R X, \\
X & =\frac{G-P}{R-P} \times 100 \%,
\end{aligned}
$$

where $P$ is the precipitation stable isotope value, $R$ is the river water stable isotope value, $G$ is the groundwater stable isotope value, $V_{\mathrm{p}}$ is the amount of precipitation, $V_{\mathrm{R}}$ is the amount of river water, $X$ is the recharge proportion of river water, and $(1-X)$ is the recharge proportion of precipitation.

According to the groundwater level in June 2011, two profiles were chosen to calculate the recharge of groundwater from the Hun River. The values of $\delta^{2} \mathrm{H}_{\text {water }}$ and $\delta^{18} \mathrm{O}_{\text {water }}$ in river water and rain were used as the endpoints for calculating groundwater recharge. Using the results of $\delta^{2} \mathrm{H}_{\text {water }}$ and $\delta^{18} \mathrm{O}_{\text {water }}$ in groundwater, river, and rain samples (Section I and II in Table 6), the recharge ratios of the Hun River to the groundwater are $55.56 \%-86.60 \%$, respectively, and average value is $74.04 \%$.

For September 2012, two profiles were chosen according to the groundwater level. Using the results of $\delta^{2} \mathrm{H}_{\text {water }}$ and $\delta^{18} \mathrm{O}_{\text {water }}$ in groundwater, river, and rain samples (Section III and IV in Table 6) the recharge ratios of the Hun River to groundwater are $30.97 \%-63.79 \%$, respectively, and average value is $47.92 \%$.

The recharge ratios of the Hun River to the groundwater in the dry season were about $55.56 \%-86.60 \%$, and the ratio in the wet season was about $30.97 \%-63.79 \%$. The difference in recharge ratio between the two seasons may be caused by seasonal variations and changes in groundwater exploitation 


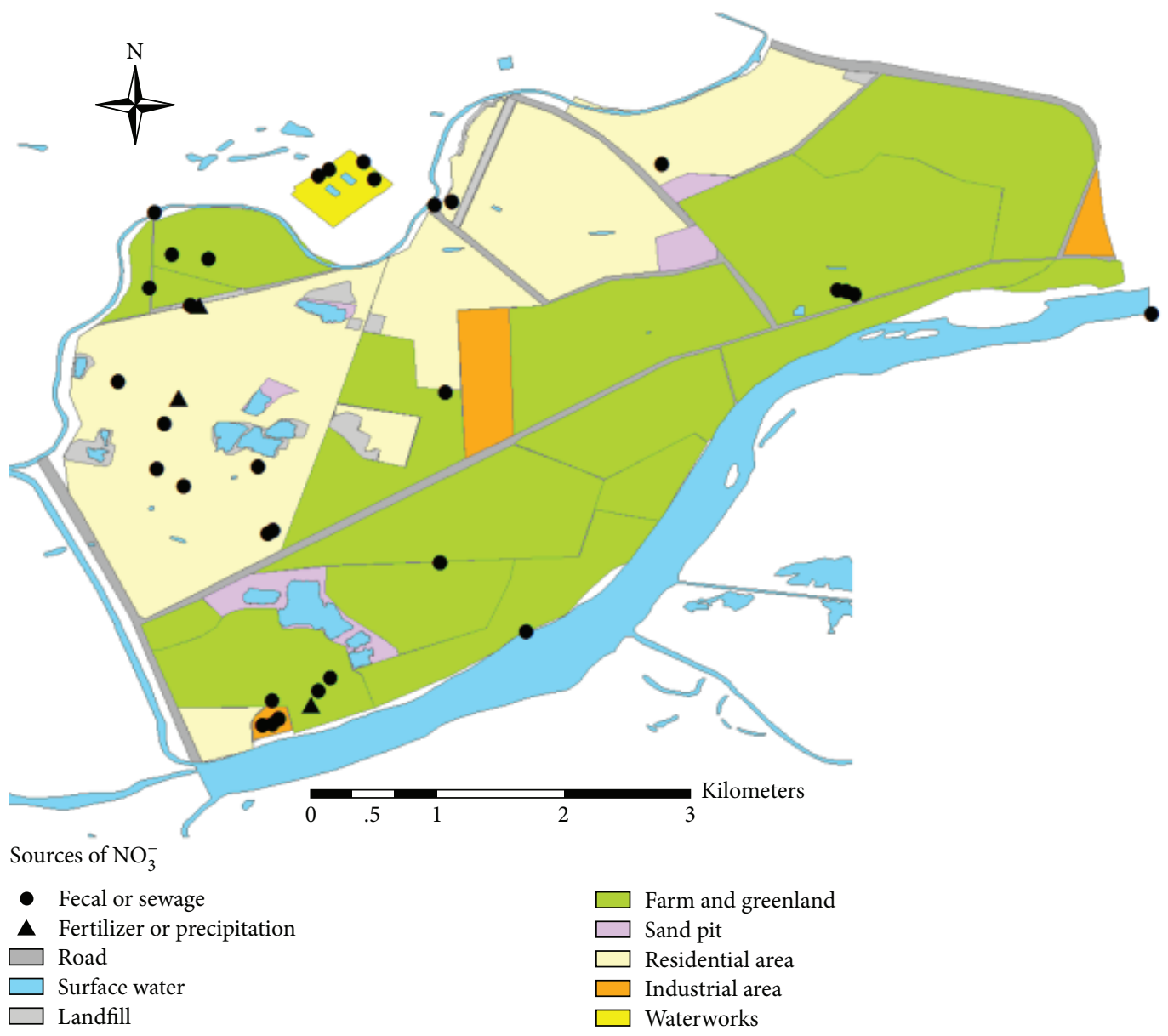

FIgURE 5: Nitrogen source spatial distribution in groundwater, September 2012.

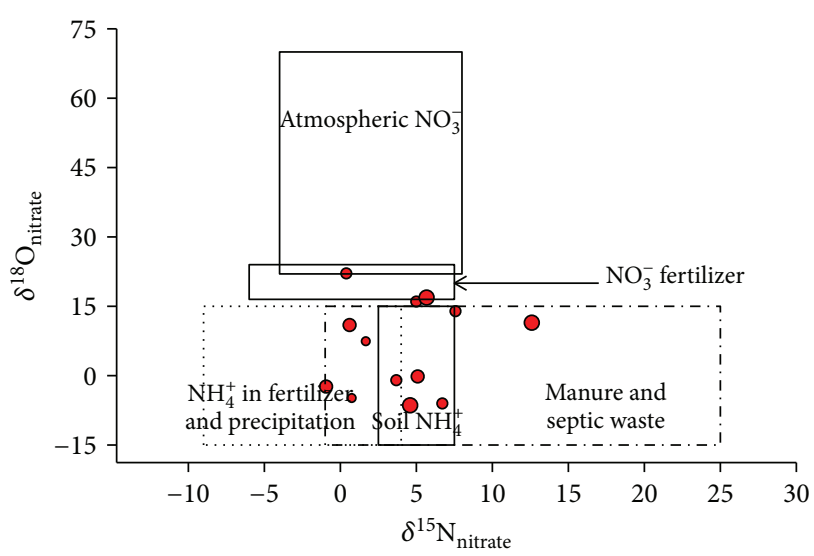

- Soil-sampling sites

Figure 6: Dual-isotope method for nitrate source attribution in soil, September 2012. Modified from Fenech et al. [33].

intensity in the water source wells. In June 2011, the water source wells were in the mining state, and when the sample was taken in September 2012, the water source wells were almost not in use.
4.5. Source Identification of Groundwater Nitrogen Contamination. A key objective was to identify the sources of nitrogen pollution in the groundwater. Isotopic composition can be used to identify sources of groundwater contamination. Because different sources of $\mathrm{NO}_{3}{ }^{-}$have different $\delta^{15} \mathrm{~N}_{\text {nitrate }}$ and $\delta^{18} \mathrm{O}_{\text {nitrate }}$ values, we identified the major contaminant source of $\mathrm{NO}_{3}{ }^{-}$in groundwater by detecting the $\mathrm{NO}_{3}{ }^{-}$isotopic composition in this study. Figure 4 shows the $\delta^{15} \mathrm{~N}_{\text {nitrate }}$ and $\delta^{18} \mathrm{O}_{\text {nitrate }}$ values for the sample in the study area and the typical ranges for the major possible sources of $\mathrm{NO}_{3}{ }^{-}[33,34]$. The main source of nitrogen could be attributed to the manure and septic waste by human activities, and the distribution of various nitrogen sources is shown in Figure 5. By using an isotopic source apportionment model based on the bias analysis of SIAR, Wang (2016) also found that the contribution rate of manure and sewage contamination is much higher than that of the other sources, reaching $76 \%-86 \%$ in the northern part of the study area.

In addition, soil samples were collected for the analysis of nitrogen and oxygen isotopes. Figure 6 shows the $\delta^{15} \mathrm{~N}_{\text {nitrate }}$ versus $\delta^{18} \mathrm{O}_{\text {nitrate }}$ values for soil samples and different sources. It indicates that in the soil, $\delta^{15} \mathrm{~N}_{\text {nitrate }}$ values range from $-10 \%$ o to $+15 \%$. 


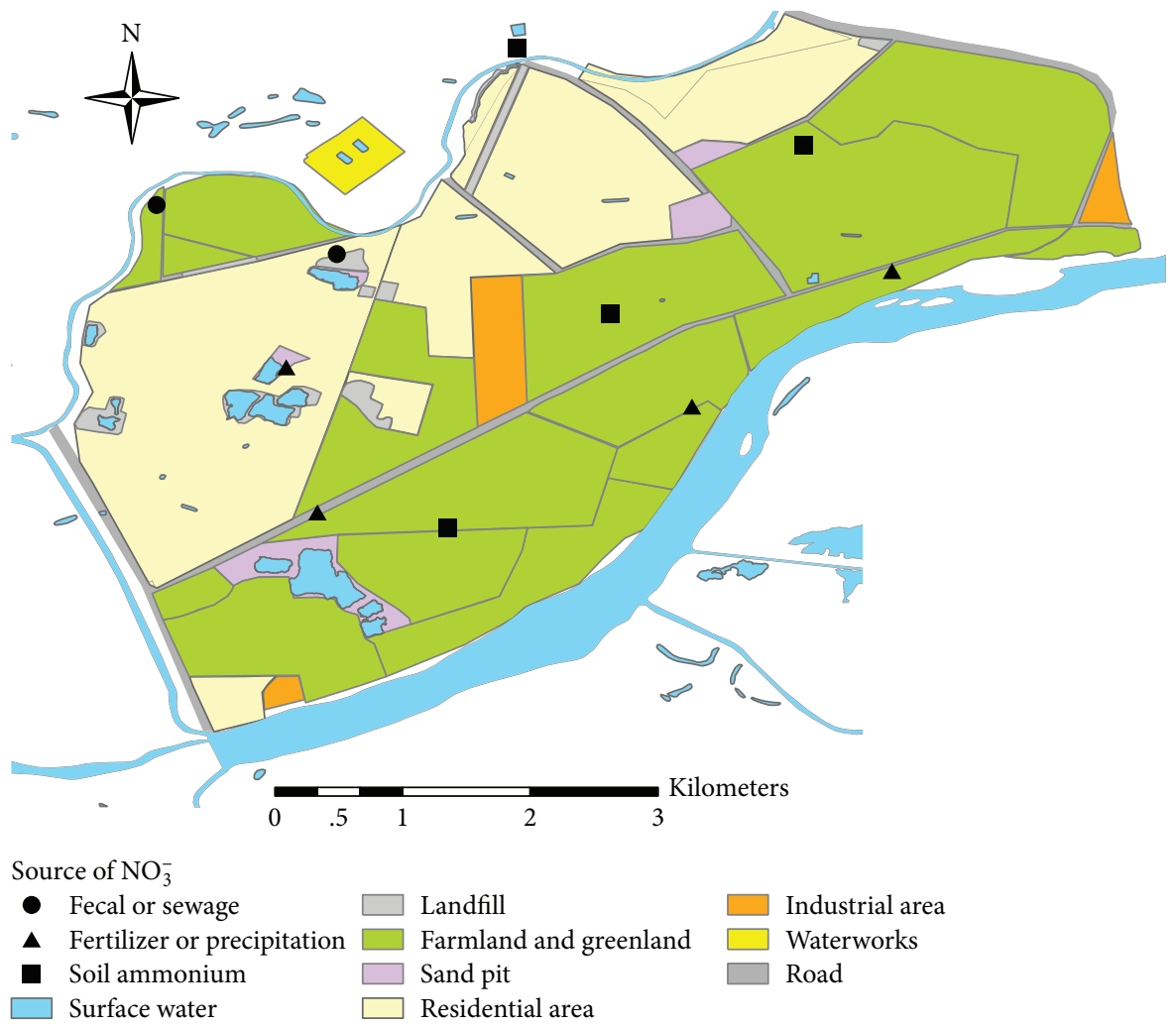

FIGURE 7: Sample point distribution and its nitrate source of soil samples in September 2012.

The location of the soil samples and the actual utilization of land showed in Figure 7 indicates that soil samples affected by manure and sewage were mainly distributed in the northwest of the study area. This was consistent with the analysis above; that is, groundwater pollution mainly results from manure and sewage infiltration [20, 21]. Nitrate in soil, originating from ammonium contained in soil input by fertilizers and precipitation, is mainly located in the southern part of the study area. This is consistent with the actual situation in the south area, mainly for farmland and green land.

\section{Conclusions}

In this paper, we used multiproxy analysis encompassing environmental isotopes and hydrochemical data to investigate the interactions between surface water and groundwater, as well as to identify the source of nitrogen contamination in groundwater in Shenyang city, China. Our work leads to the following major conclusions.

(1) Water from the Hun River with an enriched isotopic signature moves downwards and laterally and mixes with the lower-gradient groundwater. The use of $\delta^{2} \mathrm{H}_{\text {water }}$ and $\delta^{18} \mathrm{O}_{\text {water }}$ in surface water and groundwater indicated that river water accounted for around $55.56 \%-86.60 \%$ of the total groundwater recharge in the dry season, and the ratio changed to $30.97 \%-$ $63.79 \%$ in the wet season. The huge supply of groundwater indicates that groundwater is highly susceptible to contamination from land surface activities.

(2) Stable isotope analyses combined with the chemical and hydrogeological data from this study site indicate that the human activities, such as manure and sewage discharge, are the prevailing source of nitrogen in the waters. This will be useful for future management and decisions to control pollution sources and protect groundwater quality.

\section{Conflicts of Interest}

The authors declare that there is no conflict of interest regarding the publication of this paper.

\section{Acknowledgments}

The studies described in this paper were funded jointly by the 863 Program (2007AA06A410) of the Chinese Ministry of Science and Technology, the National Natural Science Foundation of China (no. 41572225), and the Studies of Safety Evaluation and Pollution Prevention Technology and Demonstration for Groundwater Resources in Beijing (D07050601510000).

\section{Supplementary Materials}

The original data of Table 2 are listed in Table S1. The original data of Table 3 are listed in Table S2. The original data of 
Table 4 are listed in Table S3 for the dry season and in Table S4 for the wet season. The original data of Table 5 are listed in Table S5 for the dry season and in Table S6 for the wet season. The $\delta^{15} \mathrm{~N}_{\text {nitrate }}$ and $\delta^{18} \mathrm{O}_{\text {nitrate }}$ values for soil samples are listed in Table S7. (Supplementary Materials)

\section{References}

[1] M. Brunke and T. Gonser, "The ecological significance of exchange processes between rivers and groundwater," Freshwater Biology, vol. 37, no. 1, pp. 1-33, 1997.

[2] S. Krause, A. Bronstert, and E. Zehe, "Groundwater-surface water interactions in a north German lowland floodplainimplications for the river discharge dynamics and riparian water balance," Journal of Hydrology, vol. 347, no. 3-4, pp. 404-417, 2007.

[3] M. Sophocleous, "Interactions between groundwater and surface water: the state of the science," Hydrogeology Journal, vol. 10, no. 2, pp. 348-348, 2002.

[4] D. O. Whittemore, M. S. Tsou, and C. Mcelwee, Arkansas River Salinity and Contamination of the High Plains Aquifer. Challenges Facing Irrigation and Drainage in the New Millennium, Proceedings Us Committee on Irrigation and Drainage, Fort Collins, Colorado, USA, 2000.

[5] S. W. Chapman, B. L. Parker, J. A. Cherry, R. Aravena, and D. Hunkeler, "Groundwater-surface water interaction and its role on TCE groundwater plume attenuation," Journal of Contaminant Hydrology, vol. 91, no. 3-4, pp. 203-232, 2007.

[6] R. S. Gabor, S. J. Hall, D. P. Eiriksson et al., "Persistent urban influence on surface water quality via impacted groundwater," Environmental Science \& Technology, vol. 51, no. 17, pp. 94779487, 2017.

[7] D. W. Rassam, D. E. Pagendam, and H. M. Hunter, "Conceptualisation and application of models for groundwater-surface water interactions and nitrate attenuation potential in riparian zones," Environmental Modelling \& Software, vol. 23, no. 7, pp. 859-875, 2008.

[8] K. E. Schilling, Z. Li, and Y. K. Zhang, "Groundwater-surface water interaction in the riparian zone of an incised channel, Walnut Creek, Iowa," Journal of Hydrology, vol. 327, no. 1-2, pp. 140-150, 2006.

[9] J. Tóth, "Groundwater as a geologic agent: an overview of the causes, processes, and manifestations," Hydrogeology Journal, vol. 7, no. 1, pp. 1-14, 1999.

[10] T. C. Winter, "Relation of streams, lakes, and wetlands to groundwater flow systems," Hydrogeology Journal, vol. 7, no. 1, pp. 28-45, 1999.

[11] K. E. Bencala, V. C. Kennedy, G. W. Zellweger, A. P. Jackman, and R. J. Avanzino, "Interactions of solutes and streambed sediment: 1. An experimental analysis of cation and anion transport in a mountain stream," Water Resources Research, vol. 20, no. 12, pp. 1797-1803, 1984.

[12] T. C. Winter, "Recent advances in understanding the interaction of groundwater and surface water," Reviews of Geophysics, vol. 33, no. S2, pp. 985-994, 1995.

[13] R. Barthel and S. Banzhaf, "Groundwater and surface water interaction at the regional-scale-a review with focus on regional integrated models," Water Resources Management, vol. 30, no. 1, pp. 1-32, 2016.

[14] J. Levy and Y. Xu, "Review: groundwater management and groundwater/surface-water interaction in the context of South
African water policy," Hydrogeology Journal, vol. 20, no. 2, pp. 205-226, 2012.

[15] M. Hayashi and D. O. Rosenberry, "Effects of ground water exchange on the hydrology and ecology of surface water," Groundwater, vol. 40, no. 3, pp. 309-316, 2002.

[16] G. Hou, F. Liu, M. Liu et al., "Performance of a permeable reactive barrier for in situ removal of ammonium in groundwater," Water Science \& Technology: Water Supply, vol. 14, no. 4, p. 585, 2014.

[17] S. R. Silva, C. Kendall, D. H. Wilkison, A. C. Ziegler, C. C. Y. Chang, and R. J. Avanzino, "A new method for collection of nitrate from fresh water and the analysis of nitrogen and oxygen isotope ratios," Journal of Hydrology, vol. 228, no. 1-2, pp. 22-36, 2000.

[18] W. A. Brand, "Precon: a fully automated interface for the pre-GC concentration of trace gases on air for isotopic analysis," Isotopes in Environmental and Health Studies, vol. 31, no. 3-4, pp. 277-284, 1995.

[19] H. Koizumi, T. Nakadai, Y. Usami, M. Satoh, M. Shiyomi, and T. Oikawa, "Effect of carbon dioxide concentration on microbial respiration in soil," Ecological Research, vol. 6, no. 3, pp. 227-232, 1991.

[20] L. Y. Liu, J. T. He, and J. J. Wang, "China ordnance industry survey and Geotechnical Institute Beijing Key Laboratory of Water Resources and Environmental Engineering," in Contributions to the Source of Groundwater Nitrogen Pollution in Hun River Riparian Zone, Geotechnical Engineering Technique, 2015.

[21] Y. C. Liu, H. B. Yang, X. D. Zou et al., "Ph value in Shenyang area from 2005 to 2012," Environmental Science \& Technology, vol. 38, no. 12Q, pp. 116-119, 2015.

[22] D. Su, X. S. Su, L. H. Zhang et al., "Redox zonation in the process of river water infiltration in the Huangjia riverside well field, Shenyang City," China Environmental Science, vol. 36, no. 7, pp. 2043-2050, 2016.

[23] W. Z. Yuan, Biogeochemical Process of Fe and Mn during River Bank Infiltration Affected by Groundwater Exploiting, Doctoral dissertation, Jilin University, 2017.

[24] M. M. Abd El-Salam, E. M. El-Ghitany, and M. M. Kassem, "Quality of bottled water brands in Egypt part i: physicochemical analyses," The Journal of the Egyptian Public Health Association, vol. 83, no. 5-6, pp. 369-388, 2008.

[25] X. S. He, H. Yu, B. D. Xi, D. Y. Cui, H. W. Pan, and D. Li, "Difference of contaminant composition between landfill leachates and groundwater and its reasons," Science, vol. 35, no. 4, pp. 1399-1406, 2014.

[26] N. Shan, Research on Nitrogen Numerical Simulation of Typical Riverside Source Field, Dissertation, China University of Geosciences (Beijing), 2011.

[27] H. Craig, "Isotopic variations in meteoric waters," Science, vol. 133, no. 3465, pp. 1702-1703, 1961.

[28] W. Dansgaard, "Stable isotopes in precipitation," Tellus, vol. 16, no. 4, pp. 436-468, 1964.

[29] T. Coplen, "Stable isotope hydrology: deuterium and oxygen18 in the water cycle," Eos, Transactions American Geophysical Union, vol. 63, no. 45, pp. 861-862, 1982.

[30] D. A. Streletskiy, N. I. Tananaev, T. Opel et al., "Permafrost hydrology in changing climatic conditions: seasonal variability of stable isotope composition in rivers in discontinuous permafrost," Environmental Research Letters, vol. 10, no. 9, article 095003, 2015. 
[31] Q. Yang, H. Xiao, L. Zhao et al., "Hydrological and isotopic characterization of river water, groundwater, and groundwater recharge in the Heihe River basin, northwestern China," Hydrological Processes, vol. 25, no. 8, pp. 1271-1283, 2011.

[32] I. D. Clark and P. Fritz, Environmental Isotopes in Hydrology, vol. 80, no. 5, 1998, Boca Raton Fla Lewis Publishers, 1998, .

[33] C. Fenech, L. Rock, K. Nolan, J. Tobin, and A. Morrissey, "The potential for a suite of isotope and chemical markers to differentiate sources of nitrate contamination: a review," Water Research, vol. 46, no. 7, pp. 2023-2041, 2012.

[34] C. Kendall, "Tracing nitrogen sources and cycling in catchments," in Isotope Tracers in Catchment Hydrology, pp. 519-576, Elsevier, Amsterdam, 1998. 

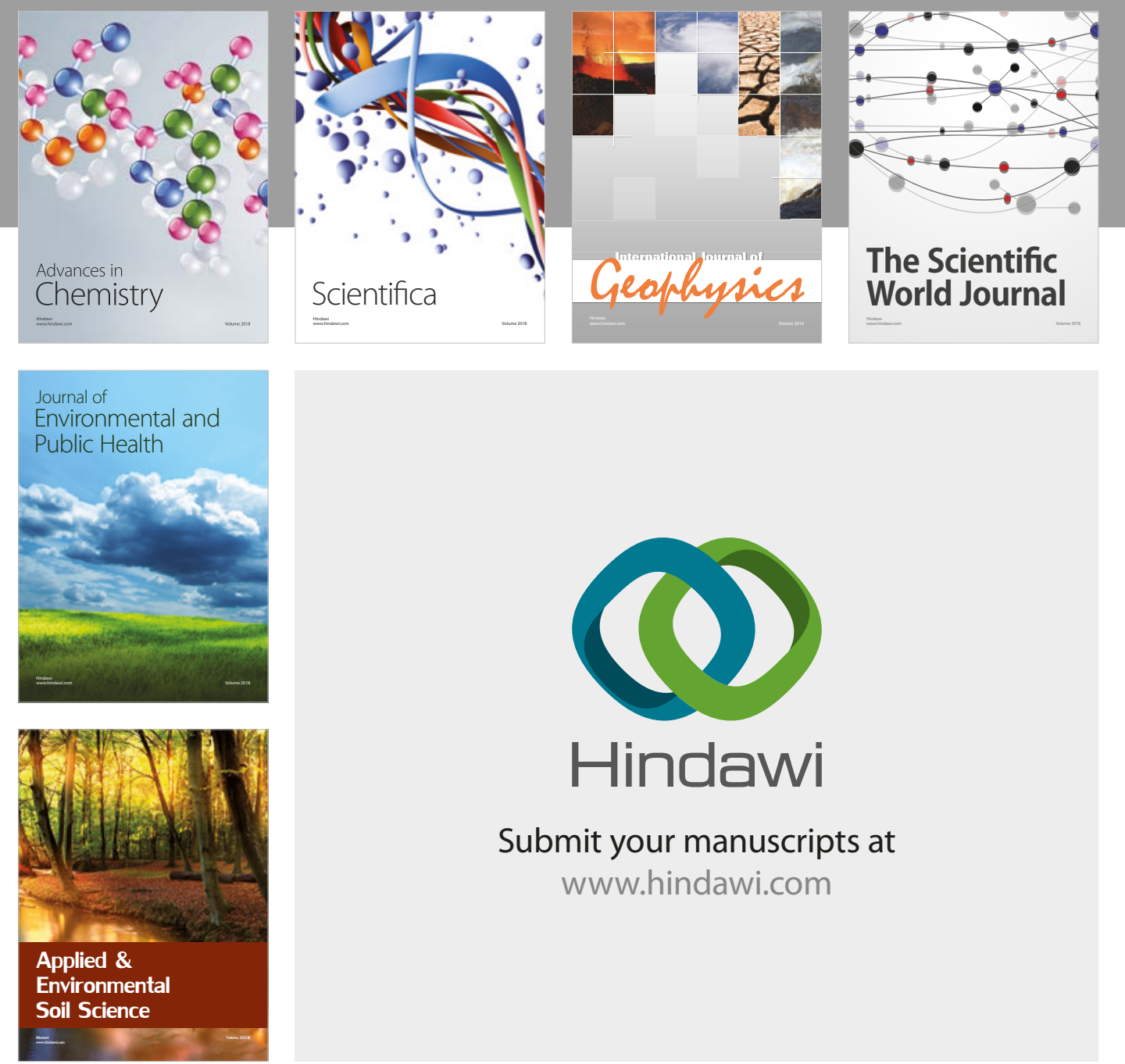

The Scientific

\section{World Journal}
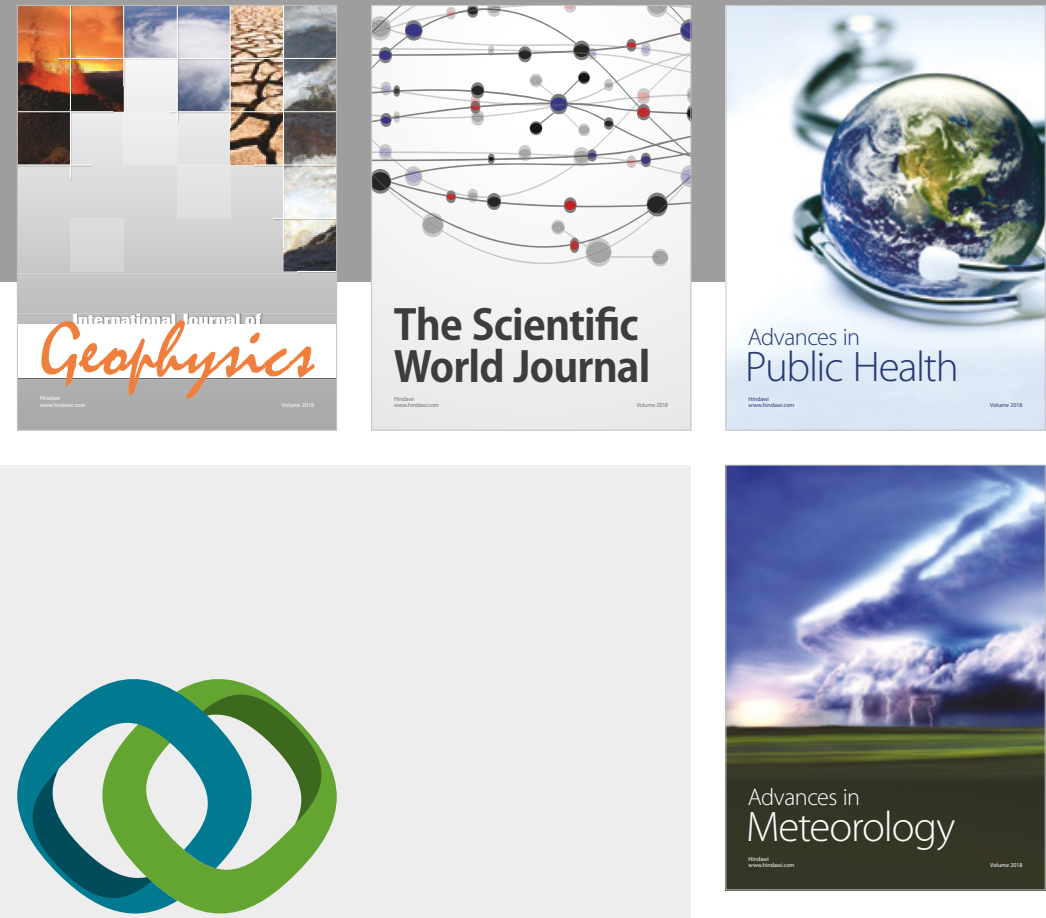

Advan

Public Health

\section{Hindawi}

Submit your manuscripts at

www.hindawi.com
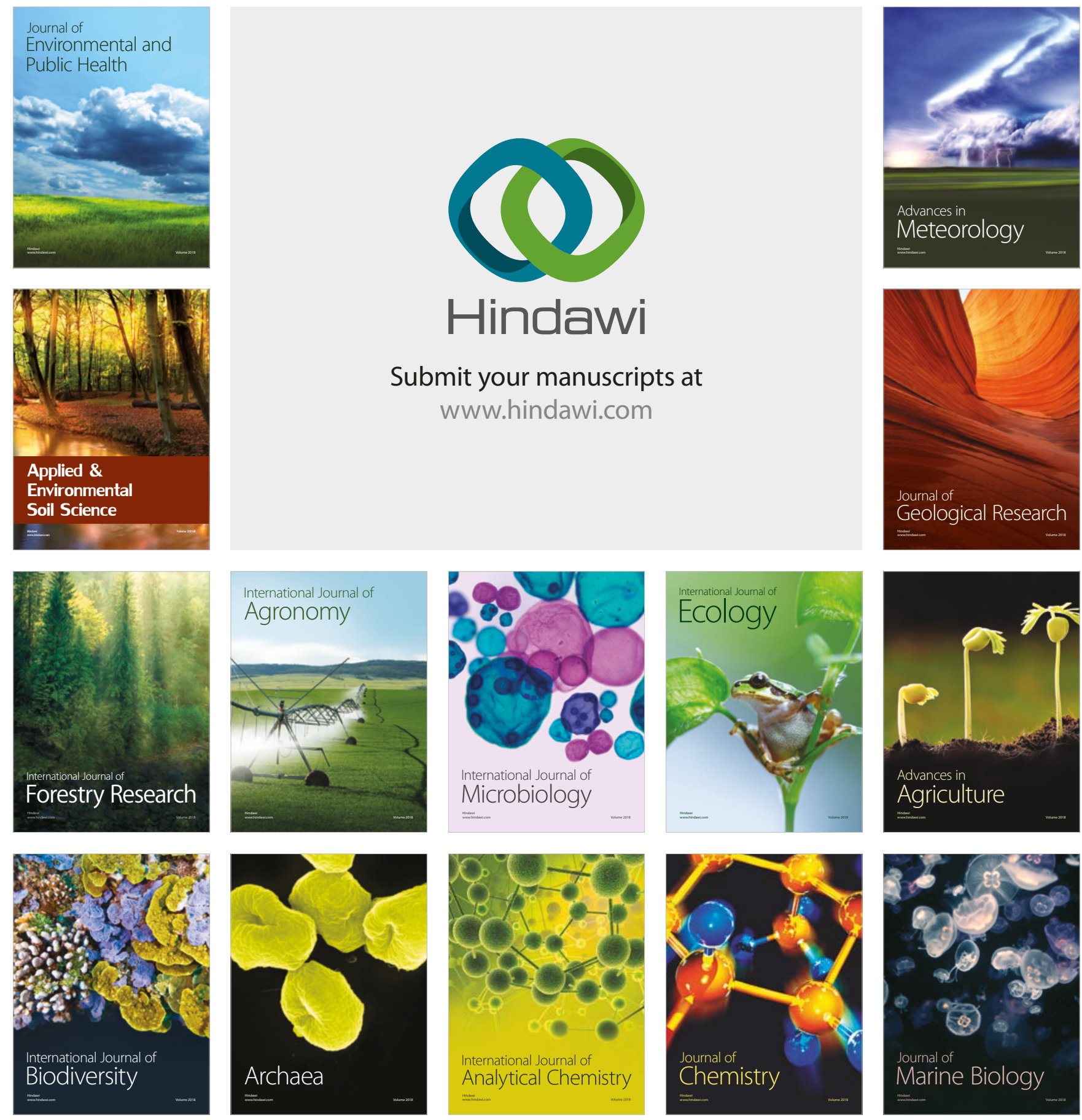